\title{
Incidence of Acute Kidney Injury in HCV Infected Patients Receiving Direct-Acting Antivirals Hayam Aref ${ }^{1}$, Mostafa Ahmed ${ }^{2}$, Ahmed Abdelmoniem Emara*1, Salma Fathy Rezk ${ }^{1}$, Haitham Ezzat Abdelaziz ${ }^{1}$ \\ ${ }^{1}$ Department of Internal Medicine and Nephrology, Ain Shams University, Cairo, Egypt \\ ${ }^{2}$ Kobry El Kobba Military Hospital, Cairo, Egypt
}

*Corresponding author: Ahmed Abdelmoniem Emara, Mobile: +201006721401, E-mail: ahmed_emara@med.asu.edu.eg

\begin{abstract}
Background: Egypt had high burden of HCV infection worldwide. The new direct-acting antivirals (DAAs) can target almost all steps of HCV life cycle.

Objective: Study of the incidence of acute kidney injury (AKI) in HCV infected patients receiving DAAs.

Patients and methods: A prospective study that was conducted in the Virology Clinic in Kobry El-Koba Military Hospital on 63 male patients who were eligible to treatment by DAAs, who received treatment with sofosbuvir, daclatasvir and ribavirin combination. They were divided into Group A: 33 patients with eGFR > $90 \mathrm{ml} / \mathrm{min}$ and Group B: 30 patients with chronic kidney disease (CKD) stage II-III (eGFR $<90$ and $>30 \mathrm{~mL} / \mathrm{min}$ ). The fluctuations in serum creatinine and eGFR were measured while on-therapy and for 3 months follow up after end of treatment.

Results: total of 63 male patients, treatment-naive were included. Group A (33 patients) with eGFR $>90 \mathrm{~mL} / \mathrm{min}$. Group B (30 patients) with eGFR $<90 \mathrm{~mL} / \mathrm{min}$. There was a significant difference between different readings of serum creatinine in both groups on therapy and on follow up during the next 3 months after the end of therapy. The incidence of AKI was more observed in patients with eGFR $>90 \mathrm{ml} / \mathrm{min}$ in comparison with those with eGFR $<90$ $\mathrm{ml} / \mathrm{min}$ and $>45 \mathrm{ml} / \mathrm{min}$, but with no statistical significance.

Conclusion: AKI events during and after end of therapy with DAAs were observed especially in patients with normal baseline serum creatinine. Patients with CKD stage II-III experienced improvement in their kidney functions during and after end of therapy.
\end{abstract}

Keywords: Hepatitis C virus, Direct acting new antiviral drugs, Acute kidney injury.

\section{INTRODUCTION}

A cross sectional survey was conducted by the Egyptian Demographic Health Survey (EDHS) in 2008 on a large nationally representative sample including hepatitis $\mathrm{C}$ virus (HCV) biomarkers. It estimated the prevalence of $\mathrm{HCV}$ among the 15-59 years age group to be $14.7 \%^{(1)}$. According to this data, Egypt has the highest HCV prevalence worldwide ${ }^{(2)}$.

$\mathrm{Up}$ to $25 \%$ of chronically infected $\mathrm{HCV}$ patients eventually develop cirrhosis and related complications, which include hepatocellular carcinoma $^{(3)}$.

Treatment success of HCV has been defined in terms of sustained virologic response (SVR), which is the absence of detectable levels of viral RNA in the blood after 24 weeks of completion of therapy ${ }^{(4)}$.

The new direct acting new antiviral agents (DAAs) target the HCV-encoded proteins involved with replication. These include non-structural (NS) components, such as RNA- dependent RNA polymerase (NSSB), the protein NSSA (a role in the formation of the replication complex), and the proteins NS3 and NS4A (serine protease and cofactor) ${ }^{(5)}$.

The fixed-dose combinations currently available include sofosbuvir/ledipesvir $(400 \mathrm{mg} / 90$ $\mathrm{mg}$ ), ombitasvir/peritaprevir/ ritonavir (two pills of $12.5 \mathrm{mg} / 75 \mathrm{mg} / 50 \mathrm{mg}$ of each agent, respectively) plus dasabuvir (250 mg), sofosbuvir/daclatasvir (400 mg/60 $\mathrm{mg}$ ), sofosbuvir/simeprevir (400 mg /150 mg) and ribavirin. According to KDIGO (Kidney Disease: Improving Global Outcomes) guidelines (6), AKI is defined as any of the following; increase in serum creatinine by $\geq 0.3 \mathrm{mg} / \mathrm{dL}$ within 48 hours; or increase in serum creatinine to $\geq 1.5$ times of baseline, which have occurred within the prior 7 days; or urine volume $<0.5 \mathrm{ml} / \mathrm{kg} / \mathrm{hr}$ for 6 hours ${ }^{(6)}$.

Unfortunately, there are no randomized clinical trials that document the definitive effect of treatment on renal or patient survival. The available data are obtained from small cohorts, treated with the old interferon/ribavirin protocols. Metanalysis of these studies has displayed conflicting data, which may be related to heterogenecity of patient demographics, stage and the nature of kidney disease, the extent of liver injury and associated extrarenal manifestations, e.g. cryoglobulinemia.

In a metanalysis of 11 studies comprising 107 patients treated with interferon with or without ribavirin, there was a regression in proteinuria to a variable extent in those who achieved end-of-treatment viral response. A few patients developed relapse when the viral clearance was un-sustained. There was no significant change in serum creatinine in all studies apart from 2, where the GFR was increased. No report of post-treatment biopsy ${ }^{(7)}$.

Sofosbuvir is eliminated mainly by the renal route and its use in CKD stage 4 or 5 or in patients on haemodialysis is out of the licence recommendations. The substantially higher concentrations of sofosbuvir and, its renally excreted metabolite GS- 331007 as compared to patients without renal impairment have raised more concerns. In the target 2.0 real world 
cohort study, progressive worsening of renal function and renal symptoms were reported in patients with advanced renal disease receiving a sofosbuvir-based regimen, although efficacy was equal to that observed in patients without renal disease ${ }^{(8)}$.

In our study we tried to address the effect of new DAAs on kidney functions and the possibility of occurrence of AKI and its incidence in patients with normal and impaired kidney function.

\section{PATIENTS AND METHODS}

This prospective observational study was conducted in Virology Clinic in Kobry El-Koba Military Armed Forces Hospital on adult male patients (>18years) who are HCV antibody and PCR positive, treatment-naive and eligible to treatment by DAAs drugs according to the national guidelines. They were be followed up during receiving sofosbuvir, daclatasvir and ribavirin for 3 months and for another 3 months after the end of treatment. Patients who discontinued were excluded.

All individuals included in this study underwent laboratory investigations that include CBC, liver function and renal function tests, PT, PTT and INR and abdominal ultrasound. They were divided into two groups:

Group A: 33 patients with eGFR $>90 \mathrm{ml} / \mathrm{min} / 1.73 \mathrm{~m}^{2}$. Group B: 30 patients with CKD with eGFR >30 $\mathrm{mL} / \mathrm{min}$ stage II $($ GFR $=60-89 \mathrm{~mL} / \mathrm{min}) \&$ IIIa $($ GFR $=45-59 \mathrm{~mL} / \mathrm{min})$ and IIIb $(\mathrm{GFR}=30-44 \mathrm{~mL} / \mathrm{min})$. It is estimated using CKD-EPI equation.

\section{Study exclusion criteria:}

Patients were excluded from the study if they met any of the following criteria: co-infection with hepatitis B virus, patients with advanced liver disease (Child B or C), portal vein thrombosis or hepatocellular carcinoma. Also, patients with clinically significant illness including psychiatric or cardiac diseases or any other medical disorder that may interfere with subject treatment and/or adherence to protocol, patients who developed drop in haemoglobin level, patients with eGFR less than or equal to 30 $\mathrm{ml} / \mathrm{min} / 1.73 \mathrm{~m}^{2}$ and patients with prior exposure to a DAA (irrespective of duration).

Baseline kidney function was determined by averaging all outpatient creatinine values available in the electronic medical record in the 3 months before starting DAAs therapy. During treatment, serum creatinine levels after end of $1^{\text {st }}$ month and $3^{\text {rd }}$ month were recorded and their corresponding eGFRs were estimated. After end of treatment, serum creatinine levels were recorded after end of $4^{\text {th }}, 5^{\text {th }}$ and $6^{\text {th }}$ months of start of treatment and their corresponding eGFRs were estimated. GFR was estimated using Chronic Kidney Disease Epidemiology Collaboration (CKDEPI) equation as follows:
GFR $=141 \mathrm{X} \min (\mathrm{Scr} / \kappa, 1)^{\alpha} \mathrm{X} \max (\mathrm{Scr} / \kappa, 1)^{-1.209} \mathrm{X}$ $0.993^{\mathrm{Age}}$ X 1.018 [if female] X 1.159 [if black]

Scr is serum creatinine $(\mathrm{mg} / \mathrm{dL}), \kappa$ is 0.7 for females and 0.9 for males, $\alpha$ is -0.329 for females and -0.411 for males, min indicates the minimum of $\mathrm{Scr} / \mathrm{\kappa}$ or 1 , and max indicates the maximum of $\mathrm{Scr} / \kappa$ or 1 .

The primary end point was evaluation of sustained virological response (SVR) to antiviral treatment by PCR for HCV RNA at 12-week SVR 12 (time frame from 12 weeks after end of treatment). Patients with prior exposure to a DAA (irrespective of duration), portal vein thrombosis or hepatocellular carcinoma were excluded.

Virological response was assessed by measuring serum HCV RNA concentration after 4 weeks of treatment (rapid virological response [RVR]), at the end of the scheduled 12 or 24 weeks of treatment (end-of-treatment response [ETR]) and 12 weeks after stopping treatment (sustained virological response [SVR12]). 62 patients achieved RVR, ETR and SVR. Only one patient continued treatment for 24 weeks.

The secondary end point was occurrence of AKI (time frame from start of treatment to 12 weeks after end of treatment).

\section{Ethical approval:}

The study protocol was reviewed and approved by Ethical Committee of Faculty of Medicine, Ain shams University and a signed written from each patient was obtained.

Treatment protocol: Daclatasvir $60 \mathrm{mg}$, sofosbuvir $400 \mathrm{mg}$ and ribavirin $200 \mathrm{mg}$ for 12 weeks.

\section{Statistical analysis}

Quantitative data were presented as mean, standard deviation (SD) and range values. Independent t- test was used for comparing quantitative variables (eGFR $\&$ Creat) readings between group $\mathrm{A}$ and $\mathrm{B}$ and $\mathrm{p}$-value $\leq 0.05$ was considered significant. Qualitative data were presented as number and percentage. Fisher exact test was done for comparing qualitative variables (AKI) between group A and B and p-value $\leq 0.05$ was considered significant. Repeated measure ANOVA test was used for comparing quantitative variables (eGFR \& Creat) readings overtime, and different readings overtime between groups A \& B and p-value $\leq 0.05$ was considered significant. Statistical analysis was performed with IBM ${ }^{\circledR}$ SPSS $®$ Statistics Version 20 for Windows.

\section{RESULTS}

The study enrolled 80 male patients with active $\mathrm{HCV}$ infection who were presented to the Virology Clinic in Kobry El-Koba Military Armed Forces Hospital between April 2017 and November 2017. They received DAA-based anti-HCV therapy in the form daclatasvir $60 \mathrm{mg}$, sofosbuvir $400 \mathrm{mg}$ and ribavirin $200 \mathrm{mg}$ for 12 weeks. 17 patients of which 
were excluded (11 of which lost follow up; and another 6 did not achieve RVR). The remaining 63 patients were of mean age 57.7 years old. 54\% had liver cirrhosis. 33 patients (group A) with normal kidney functions (eGFR $>90 \mathrm{ml} / \mathrm{min}$ ) and 30 patients (group B) with CKD with eGFR $>30 \mathrm{~mL} / \mathrm{min}$ and $<90 \mathrm{~mL} / \mathrm{min}$. Only one CKD patient continued treatment for 6 months (because he had a detectable HCV RNA after 1 month of starting treatment). All other patients completed the treatment for 3 months. A total of $98.5 \%(62 / 63)$ of the patients achieved SVR at $12^{\text {th }}$ week (SVR 12). $4.8 \%$ developed a drop-in haemoglobin level of more than $2.5 \mathrm{~g} / \mathrm{dL}$ without incidence of AKI. Changes of serum creatinine level and eGFR were followed up during 3 months of treatment and for 3 months after end of treatment. The main demographic characteristics are described in table (1).

Table (1): The main demographic characteristics of the study population

\begin{tabular}{|c|c|c|c|c|c|c|}
\hline \multirow[t]{2}{*}{$x^{2}+x^{2}$} & \multicolumn{2}{|c|}{ Group A } & \multicolumn{2}{|c|}{ Group B } & \multirow{2}{*}{$\begin{array}{c}\text { Independent } \\
\text { t test }\end{array}$} & \multirow[t]{2}{*}{$\mathbf{P}$} \\
\hline & Mean & \pm SD & Mean & \pm SD & & \\
\hline Age & 53.8 & 11.0 & 62.4 & 7.4 & -3.629 & $.001 *$ \\
\hline $\mathrm{Hb}(\mathrm{g} / \mathrm{dL})$ & 14.6 & 1.7 & 14.6 & 1.6 & .033 & 974 \\
\hline PLT $\left(10^{3} / \mathrm{uL}\right)$ & 200.9 & 45.0 & 201.8 & 41.0 & $\begin{array}{l}.079 \\
\end{array}$ & .937 \\
\hline AST (IU/L) & 51.7 & 5.7 & 48.1 & 4.3 & .579 & .565 \\
\hline ALT (IU/L) & 55.9 & 3.1 & 42.9 & 7.9 & 1.678 & .098 \\
\hline Total bil. $(\mathrm{mg} / \mathrm{dL})$ & .8 & .04 & .9 & .04 & -.773 & .442 \\
\hline Albumin (g/dL) & 4.3 & .5 & 4.5 & .4 & -1.985 & .052 \\
\hline INR & 1.0 & .1 & 1.0 & .01 & -.571 & .570 \\
\hline $\begin{array}{c}\text { Baseline serum } \\
\text { creatinine }(\mathrm{mg} / \mathrm{dL})\end{array}$ & .9 & .2 & 1.2 & .2 & -9.344 & $.000^{*}$ \\
\hline Baseline eGFR & 112.7 & 14.8 & 72.7 & 11.9 & 11.745 & $.000^{*}$ \\
\hline
\end{tabular}

The mean ages of group A and group B were $53.8 \pm 11$ and $62.4 \pm 7.4$ years respectively $(\mathrm{P}=0.001)$; all were male; treatment-naive; and 53\% had cirrhosis by pelviabdominal ultrasound. The mean values for baseline eGFR and serum creatinine (Scr) for group I were $112.7 \pm 14.8 \mathrm{ml} / \mathrm{min} / 1.73 \mathrm{~m}^{2}$ and $0.9 \pm 0.15 \mathrm{mg} / \mathrm{dL}$ respectively. Those for group II were $72.7 \pm 11.9$ and $1.2 \pm 0.2$ respectively. Other baseline characteristics did not differ significantly between both groups as shown in table (1).

Table (2): Difference between different readings of serum Creat. in study population

\begin{tabular}{|c|c|c|c|c|}
\hline & \multicolumn{2}{|c|}{ Group A } & \multicolumn{2}{c|}{ Group B } \\
\hline & Mean & SD & Mean & SD \\
\hline Creat 0 & $0.8545^{\mathrm{a}}$ & .15019 & $1.2500^{\mathrm{a}}$ & .18523 \\
\hline Creat 1 & $0.9545^{\mathrm{b}}$ & .19380 & $1.2533^{\mathrm{a}}$ & .25152 \\
\hline Creat 3 & $1.0152^{\mathrm{bc}}$ & .15637 & $1.1567^{\mathrm{b}}$ & .32450 \\
\hline Creat 4 & $0.9788^{\mathrm{b}}$ & .15960 & $1.1267^{\mathrm{b}}$ & .30164 \\
\hline Creat 5 & $0.9636^{\mathrm{b}}$ & .19173 & $1.1200^{\mathrm{b}}$ & .29873 \\
\hline Creat 6 & $0.9606^{\mathrm{b}}$ & .16945 & $1.1200^{\mathrm{b}}$ & .29054 \\
\hline F & \multicolumn{2}{|c|}{$\mathbf{6 . 2 7 8}$} & \multicolumn{2}{c|}{$\mathbf{5 . 2 3 1}^{\mathbf{0 . 0 0 1}}$} \\
\hline P & \multicolumn{2}{|c|}{} & \multicolumn{2}{c|}{} \\
\hline
\end{tabular}

Creat 0: baseline serum creatinine, Creat 1: serum creatinine after 1 month of start of treatment, Creat 3: serum creatinine after $3^{\text {rd }}$ month of start of treatment, Creat 4: serum creatinine after 4 months of start of treatment, Creat 5: serum creatinine after $5^{\text {th }}$ month of start of treatment and Creat 6 : serum creatinine after $6^{\text {th }}$ month of start of treatment.

Difference between different readings of serum creatinine in groups A \& B on therapy and on follow up during the next 3 months after end of therapy are illustrated in table (2). Significant difference between readings is denoted by different superscript. 


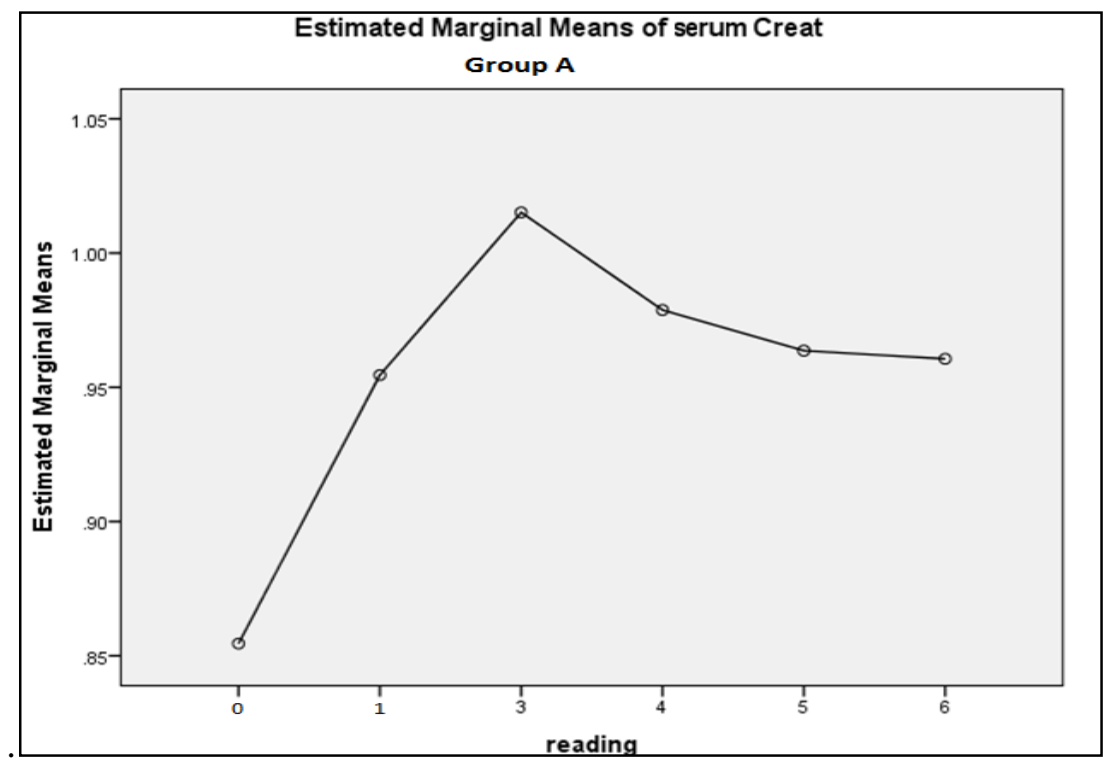

Figure (1): Estimated mean of serum creatinine in group A in each of the 6 months of follow up, 0: baseline before start of treatment where there was rise in serum creatinine during 3 months of therapy with slight improvement during follow up after end of therapy without reaching the baseline.

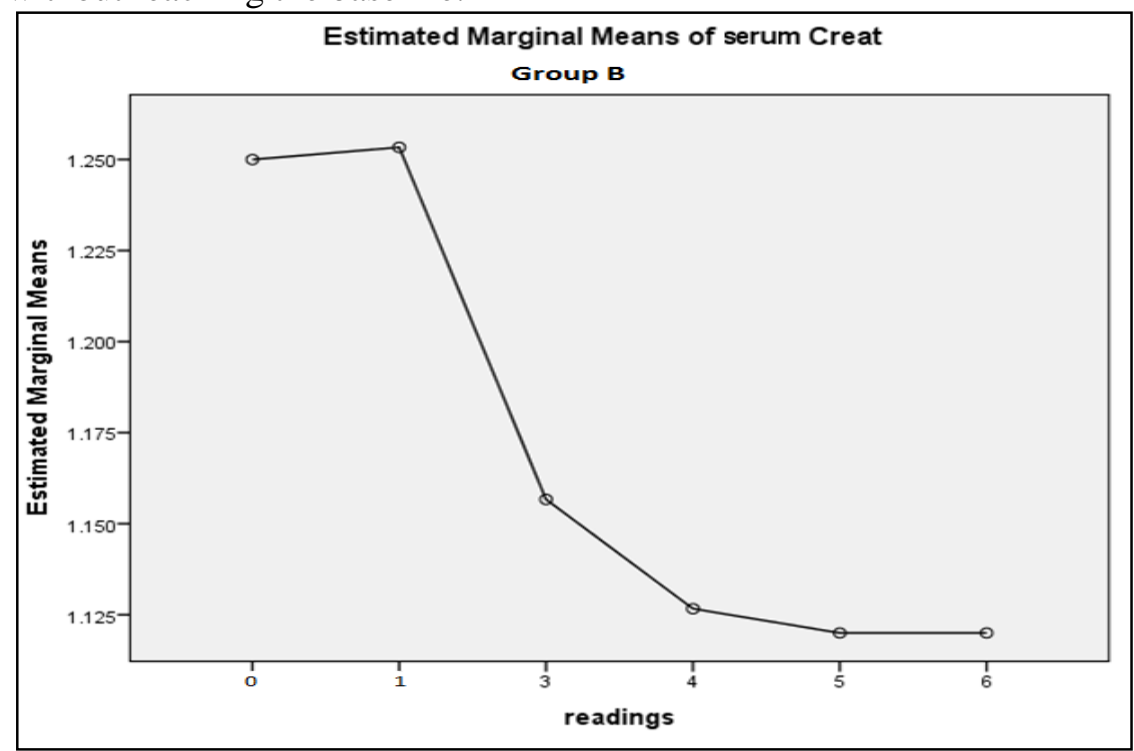

Figure (2): Estimated mean of serum creatinine in group B in each of the 6 months of follow up, 0: baseline before start of treatment where there was slight increase after $1^{\text {st }}$ month then there was significant improvement after $3^{\text {rd }}$ and $4^{\text {th }}$ months of start of therapy to come to a plateau by the end of the $6^{\text {th }}$ month.

Table (3): AKI in study population

\begin{tabular}{|c|c|c|c|c|c|c|}
\hline & \multicolumn{2}{|c|}{ Group A } & \multicolumn{2}{|c|}{ Group B } & \multirow[t]{2}{*}{$\mathbf{P}^{*}$} \\
\hline & & $\mathbf{N}$ & $\%$ & $\mathbf{N}$ & $\%$ & \\
\hline Baseline & & 33 & $100.0 \%$ & 30 & $100.0 \%$ & --- \\
\hline \multirow{2}{*}{$\begin{array}{l}\text { After } 1^{\text {st }} \\
\text { month }\end{array}$} & No AKI & 31 & $93.9 \%$ & 29 & $96.7 \%$ & \multirow[t]{2}{*}{1.000} \\
\hline & AKI & 2 & $6.1 \%$ & 1 & $3.3 \%$ & \\
\hline \multirow{2}{*}{$\begin{array}{l}\text { After } 3^{\text {rd }} \\
\text { month }\end{array}$} & No AKI & 26 & $78.8 \%$ & 29 & $96.7 \%$ & \multirow[t]{2}{*}{.056} \\
\hline & AKI & 7 & $21.2 \%$ & 1 & $3.3 \%$ & \\
\hline \multirow{2}{*}{$\begin{array}{c}\text { After } 4^{\text {th }} \\
\text { month }\end{array}$} & No AKI & 28 & $84.8 \%$ & 29 & $96.7 \%$ & \multirow[t]{2}{*}{.199} \\
\hline & AKI & 5 & $15.2 \%$ & 1 & $3.3 \%$ & \\
\hline \multirow{2}{*}{$\begin{array}{l}\text { After } 5^{\text {th }} \\
\text { month }\end{array}$} & No AKI & 28 & $84.8 \%$ & 29 & $96.7 \%$ & \multirow[t]{2}{*}{.199} \\
\hline & AKI & 5 & $15.2 \%$ & 1 & $3.3 \%$ & \\
\hline \multirow{2}{*}{$\begin{array}{c}\text { After } 6^{\text {th }} \\
\text { month }\end{array}$} & No AKI & 31 & $93.9 \%$ & 29 & $96.7 \%$ & \multirow[t]{2}{*}{1.000} \\
\hline & AKI & 2 & $6.1 \%$ & 1 & $3.3 \%$ & \\
\hline
\end{tabular}

"Fisher exact test was used

Regarding the incidence of AKI in the study population, as shown in table (3), the percentage of patients showing no AKI was higher in group A than in group B all over the period of observation, but this difference showed no statistical significance. 


\section{DISCUSSION}

In our study, we found that daclatasvir/sofosbuvir/ribavirin combination antiviral therapy was effective in patients with stage 1-3 CKD with SVR of $98.5 \%$. There were AKI events during and after the end of therapy especially in patients with normal baseline serum creatinine, but clinically not significant. Patients with CKD stage 2 and 3 experienced improvement in their kidney functions during and after end of therapy.

The main purpose of $\mathrm{HCV}$ eradication is to prevent progression of cirrhosis, liver-related complication, and HCC development. In addition to these main reasons to treat $\mathrm{HCV}$ infection in patients with CKD who are potential candidates of kidney transplantation, there is an additional reason is to prevent $\mathrm{HCV}$ specific complications associated with kidney transplantation ${ }^{(9)}$.

Despite these hepatic and extrahepatic benefits of eradicating $\mathrm{HCV}$ in $\mathrm{CKD}$ patients, traditionally accepted interferon-based therapy in CKD patients has been unsatisfactory due to its suboptimal effects and toxicity, depending on the comorbid conditions and the extent of renal impairment. Therefore, eradicating $\mathrm{HCV}$ in CKD patients has been challenging. However, the emergence of direct-acting antivirals (DAAs) has changed the treatment trend of patients with chronic hepatitis $\mathrm{C}$ infection, and the decision to treat $\mathrm{HCV}$ in CKD patients has also been less challenging ${ }^{(10)}$.

As reviewed in the literature, to the best of our knowledge, this may be the first study to study the effect of daclatasvir/sofosbuvir/ribavirin on the eGFR and to report the incidence of AKI.

This study was conducted on 63 male patients, treatment-naive, 33 patients with eGFR > 90 $\mathrm{mL} / \mathrm{min} / 1.73 \mathrm{~m}^{2}$ (group A) and 30 patients with eGFR $<\mathrm{n} 90 \mathrm{~mL} / \mathrm{min} / 1.73 \mathrm{~m}^{2}(25 \mathrm{eGFR}=60-89 \mathrm{~mL} / \mathrm{min}) \&$ (5 eGFR $=45-59 \mathrm{~mL} / \mathrm{min})$ (group B). Our included treatment regimen was daclatasvir/sofosbuvir/RBV. A total of $54 \%$ had liver cirrhosis, $98.5 \%$ (62/63) of the patients achieved SVR at $12^{\text {th }}$ week post-treatment (SVR 12). Only one CKD II patient continued treatment for 6 months because he had a detectable HCV RNA after 1 month of starting treatment. All other patients completed the treatment for 3 months. we detected that the incidence of AKI was more observed in patients with eGFR $>90 \mathrm{ml} / \mathrm{min}$ per 1.73 $\mathrm{m}^{2}$ in comparison with those with eGFR $<90 \mathrm{ml} / \mathrm{min}$ per $1.73 \mathrm{~m} 2$ and $>45 \mathrm{ml} / \mathrm{min}$ per $1.73 \mathrm{~m}^{2}$, where after $1^{\text {st }}, 3^{\text {rd }}, 4^{\text {th }}, 5^{\text {th }}$ and $6^{\text {th }}$ months of start of treatment, $6.1 \%$, $21.2 \%, \quad 15.2 \%, 15.2 \%$ and $6.1 \%$ respectively developed AKI in patients with eGFR $>90 \mathrm{ml} / \mathrm{min}$ in comparison with $3.3 \%$ in those with eGFR $<90 \mathrm{ml} / \mathrm{min}$ but of no statistical significance. 5 patients with baseline eGFR > $90 \mathrm{ml} / \mathrm{min}$ developed AKI where 3 of them recovered at $3^{\text {rd }}$ month after end of treatment while one patient with baseline $\mathrm{eGFR}=76 \mathrm{ml} / \mathrm{min}$ developed AKI.
Sise et al. ${ }^{(11)}$ studied ninety-eight patients with CKD (42\% stage 1 or 2 CKD and $58 \%$ stage 3 CKD). Their mean age was 62 years old, $78 \%$ were males and $38 \%$ of patients had cirrhosis. Overall sustained virologic response was $81 \%$ and varied by regimen used and viral genotype. Average baseline eGFR was equivalent to average on-treatment eGFR, but seven patients experienced a rise in creatinine $\geq 1.5$ times baseline while taking sofosbuvir; all but one recovered. In patients with eGFR $<60 \mathrm{ml} / \mathrm{min}$ per $1.73 \mathrm{~m} 2$ at baseline (stage $3 \mathrm{CKD}$ ), regression models showed that hepatitis $\mathrm{C}$ cure was associated with a $9.3 \mathrm{ml} / \mathrm{min}$ per $1.73 \mathrm{~m} 2$ improvement in eGFR during the 6-month post-treatment follow-up period.

This study confirmed that the regimen of sofosbuvir, daclatasvir and ribavirin was effective in patients with eGFR > $45 \mathrm{~mL} / \mathrm{min} / 1.73 \mathrm{~m} 2$ with sustained virologic response rates $4.8 \%$ and rare side effects as anemia.

In contrast to the study by Shin et al. ${ }^{(12)}$, the first real world study, which evaluated efficacy and safety of diverse sofosbuvir-containing regimen in CKD stage 3 patients and confirmed the current guideline that sofosbuvir-based regimen can be used in patients with mild to moderate renal impairment $\left(\mathrm{eGFR} \geq 30 \mathrm{~mL} / \mathrm{min} / 1.73 \mathrm{~m}^{2}\right)$. The $\mathrm{SVR}$ rate at 12 weeks after end of the therapy was $85.7 \%$. Although greater than $30 \%$ decrease of eGFR was seen in 4 out of 28 patients and renal function was subsequently improved to normal in all 4 patients.

In comparison with the study of Saxena $\boldsymbol{e t} \boldsymbol{a l}$. (13) which studied the outcomes of sofosbuvir-based regimens on patients with baseline eGFR $\leq 45$ $\mathrm{mL} / \mathrm{min} / 1.73 \mathrm{~m}^{2}$ in comparison with those with eGFR $>45 \mathrm{~mL} / \mathrm{min} / 1.73 \mathrm{~m}^{2}$, our study compared the effect between patients with eGFR $>90 \mathrm{~mL} / \mathrm{min} / 1.73 \mathrm{~m}^{2}$ to those with eGFR $<90 \mathrm{~mL} / \mathrm{min} / 1.73 \mathrm{~m}^{2}$ and $>45$ $\mathrm{mL} / \mathrm{min} / 1.73 \mathrm{~m}^{2}$ on mainly kidney functions. Saxena et $\boldsymbol{a l} .{ }^{(13)}$ reported the outcomes of sofosbuvir-based therapy on patients with renal dysfunction by using the HCV-TARGET database, which is a multicenter, realworld cohort. Of the 1789 enrolled patients, 73 had eGFR of less than $45 \mathrm{~mL} / \mathrm{min} / 1.73 \mathrm{~m}^{2}$ (18 patients with eGFR $\leq 30 \mathrm{~mL} / \mathrm{min} / 1.73 \mathrm{~m}^{2}$ and 5 patients on dialysis). These patients were compared to 1716 patients with eGFR > $45 \mathrm{~mL} / \mathrm{min} / 1.73 \mathrm{~m}^{2}$. The included treatment regimen was sofosbuvir/simeprevir at $40 \%$, sofosbuvir/ RBV at 30\%, sofosbuvir/PEG-INF/RBV at $18 \%$ and sofosbuvir/simeprevir/RBV at $11 \%$. All patients with eGFR $\leq 45 \mathrm{~mL} / \mathrm{min} / 1.73 \mathrm{~m}^{2}$ were treated with sofosbuvir $400 \mathrm{mg}$ once a day. Patients with baseline eGFR $\leq 45 \mathrm{~mL} / \mathrm{min} / 1.73 \mathrm{~m}^{2}$ had a significantly higher rate of cirrhosis (73\%) as compared to the control group (24\%). SVR12 was achieved in 53 of the $64(83 \%)$ patients with eGFR < $45 \mathrm{~mL} / \mathrm{min} / 1.73 \mathrm{~m}^{2}$. This was comparable with patients with eGFR $>45 \mathrm{~mL} / \mathrm{min} / 1.73 \mathrm{~m}^{2}$. In addition, 15 of the $17(88 \%)$ patients with eGFR $\leq 30$ 
$\mathrm{mL} / \mathrm{min} / 1.73 \mathrm{~m}^{2}$ and all 5 patients on HD at baseline achieved SVR12. However, in the safety analysis, the patients with eGFR $\leq 45 \mathrm{~mL} / \mathrm{min} / 1.73 \mathrm{~m}^{2}$ had experienced significantly higher rates of anemia $(31 \%)$, worsening of the renal function (10\%), and any serious AEs (18\%). The authors concluded that patients with renal impairment need close expert monitoring.

In our study, there was a significant difference between different readings of serum creatinine in both groups on therapy and on follow up during the next 3 months after the end of therapy. We noticed also a rise in serum creatinine in (group A) during 3 months of therapy with slight improvement during follow up after end of therapy without reaching the baseline. While in group B there was a slight increase in serum creatinine after $1^{\text {st }}$ month of start of therapy then there was a significant improvement after $3^{\text {rd }}$ and $4^{\text {th }}$ months of start of therapy to come to a plateau by the end of $6^{\text {th }}$ month (Tables $2 \& 3$ ). Estimated marginal means of s. creatinine were illustrated in figures $(1 \& 2)$.

This study suggests that CKD who undergo direct-acting antiviral treatment and achieved sustained virologic response had a kidney benefit in the form of improvement in their eGFR. This could be due to higher drug exposure to antiviral medications eliminated by the kidney or decreased effect of viremia on kidneys after treatment with DAAs. Larger studies will be needed to determine if eradication of $\mathrm{HCV}$ with DAAs therapy slows or prevents progression to ESRD in patients with CKD and $\mathrm{HCV}$.

This study has several limitations. First, the limited number of treated patients in this series limits the power. Also, only one type of regimen was studied as that was the available at the time of our study. Our finding that eGFR improvement was associated with sustained virologic response in patients with reduced eGFR at baseline, although statistically significant, had wide confidence intervals and will need to be validated in larger cohorts of patients with CKD. Assessments of proteinuria were not available before and after therapy as proteinuria also defines CKD. Further studies are needed to measure the effect of directacting antiviral therapy on proteinuria.

Future studies are needed to determine predictors of kidney recovery with HCV eradication and confirm the long-term effects of $\mathrm{HCV}$ eradication on kidney function.
Conflict of interests: The authors declared no conflict of interests.

\section{REFERENCES}

1. El-Zenati F, Way A (2017): Knowledge and prevalence of hepatitis C. Egypt demographic and health survey; 2008. Available from: https://dhsprogram.com/pubs /pdf/FR220/FR220.pdf.

2. Lavanchy D (2011): Evolving epidemiology of hepatitis C virus. Clin Microbiol Infect., 17 (2): 107-115.

3. Shepard CW, Finelli L, Alter MJ (2005): Global epidemiology of hepatitis $C$ virus infection. Lancet Infect Dis., 5 (9): 558-567.

4. Kim WR (2002): The burden of hepatitis $C$ in the United States. Hepatology, 36 (1): 30-34.

5. Ghany MG, Strader DB, Thomas DL et al. (2009): Diagnosis, management, and treatment of hepatitis C: an update. Hepatology, 49 (4): 1335-1374.

6. Kellum JA, Lameire N, Aspelin P et al. (2012): Kidney disease: improving global outcomes (KDIGO) acute kidney injury work group. KDIGO clinical practice guideline for acute kidney injury. Kidney International Supplements, 2 (1): 1-138.

7. Kardashian AA, Pockros JP (2015) New Direct-Acting Antiviral Therapies for Treatment of Chronic Hepatitis C Virus. Infection.Gastroenterol Hepatol., 11 (7): 458-466.

8. Perico N, Cattaneo D, Bikbov B et al. (2009): Hepatitis Cinfection and chronic renal diseases. Clin J Am Soc Nephrol., 4 (1): 207-20.

9. Kalantar-Zadeh K, Kilpatrick RD, McAllister CJ et al. (2007): Hepatitis $\mathrm{C}$ virus and death risk in hemodialysis patients. Journal of the American Society of Nephrology, 18 (5): 1584-1593.

10. Fabrizi F, Dixit V, Messa $P$ et al. (2008): Interferon monotherapy of chronic hepatitis $\mathrm{C}$ in dialysis patients: meta- analysis of clinical trials. Journal of Viral Hepatitis, 15 (2): 79-88.

11. Sise ME, Backman E, Ortiz G et al. (2017): Effect of sofosbuvir-based hepatitis $\mathrm{C}$ virus therapy on kidney function in patients with CKD. Clinical Journal of the American Society of Nephrology, 12 (10): 1615-1623.

12. Shin HP, Park JA, Burman B et al. (2017): Efficacy and safety of sofosbuvir-based regimens for treatment in chronic hepatitis $\mathrm{C}$ genotype 1 patients with moderately impaired renal function. Clinical and Molecular Hepatology, 23 (4): 316.

13. Saxena V, Koraishy FM, Sise ME et al. (2016): Safety and efficacy of sofosbuvir- containing regimens in hepatitis C- infected patients with impaired renal function. Liver International, 36 (6): 807-816. 